\title{
Metacognitive, Emotional, and Avoidance Predictors of Generalized Anxiety Disorder
}

\author{
Yoshinori Sugiura \\ Graduate School of Integrated Arts and Sciences, Hiroshima University, Higashi-Hiroshima City, Japan \\ Email: ysugiura@hiroshima-u.ac.jp
}

How to cite this paper: Sugiura, Y. (2017) Metacognitive, Emotional, and Avoidance Predictors of Generalized Anxiety Disorder. Psychology, 8, 636-653.

https://doi.org/10.4236/psych.2017.84041

Received: February 13, 2017

Accepted: March 25, 2017

Published: March 28, 2017

Copyright $\odot 2017$ by author and Scientific Research Publishing Inc. This work is licensed under the Creative Commons Attribution International License (CC BY 4.0).

http://creativecommons.org/licenses/by/4.0/

\begin{abstract}
Predictors of worrying and generalized anxiety disorder (GAD) were compared. First, variables related to a version of inner experience were examined. Specifically, we examined whether negative appraisals about worrying and emotions can be considered subfacets of the overarching construct of experiential avoidance. Second, we examined the relative predictive power of responsibility to continue thinking (i.e., beliefs about the need for prolonged thinking about stressful problems), a construct relating worrying to problemsolving. In two studies, consistent predictors of worrying and GAD were negative metacognitive beliefs, fear of emotions, and responsibility to continue thinking, even after controlling for neuroticism in Study 2. Experiential avoidance did not explain the independent variance in worry. The structural equation model that experiential avoidance explained negative appraisals about worrying and emotions did not fit the data well. Negative metacognitive beliefs evidenced strong predictive power, therefore, requiring particular attention in treatment. Nonetheless, fear of emotions and perceived need for perseverative thinking are candidate additional components that deserve continued investigation.
\end{abstract}

\section{Keywords}

Worry, Negative Beliefs About Worrying, Fear of Emotions, Experiential Avoidance, Responsibility to Continue Thinking

\section{Introduction}

Generalized Anxiety Disorder (GAD) is a debilitating condition that is often resistant to treatment. The cardinal feature of GAD is long-lasting, pervasive, and uncontrollable worrying (Andrews, Hobbs, Borkovec, Beesdo, \& Craske, 2010). Although there is evidence showing the efficacy of cognitive behavioral therapy 
(CBT) for GAD, there is clearly room for improvement (see Cuijpers, Sijbrandij, Koole, Huibers, Berking, \& Andersson, 2014; Hanrahan, Field, Jones, \& Davey, 2013 for a meta-analysis) and further developments in knowledge about the etiology of GAD, as well as in its treatment, are required.

There are several theoretical models of GAD. For example, a review conducted by Behar, DiMarco, Mohlman, \& Staples (2009) discussed the avoidance model, the intolerance of uncertainty model, metacognitive model, emotion dysregulation model, and acceptance-based model of GAD. These models are all multi-faceted, each taking into consideration multiple predictors in the etiology of GAD. Behar et al. reported that these models all share a common focus: the avoidance of inner experiences as at least one of the etiological factors of GAD. However, the interrelationship among etiological factors needs further elucidation. Specifically, do interventions target sufficiently many etiological dimensions, or would additional components produce incrementally beneficial therapeutic effects? Recent evidence indicates that the chronicity of GAD affects whether a focused single intervention or multi-faceted intervention is superior (Newman \& Fisher, 2013). Then, what specific psychological processes should be targeted? Overall, there has been a dearth of empirical research comparing the different variables of the various models (for exceptions, see Stapinski et al., 2010; Ruggiero et al., 2012). The study reported here addressed two theoretical questions about interrelationships among the predictors of GAD: the relative predictive power of factors reflecting the aversion of inner experiences and the relative predictive power of factors related to problem-solving.

\subsection{Relative Predictive Power of Factors Reflecting A Version of Inner Experiences}

Both the emotion dysregulation model (Mennin, Heimberg, Turk, \& Fresco, 2005) and the acceptance-based models (Roemer \& Orsillo, 2002) consider the fear of emotions to be an important predictor, whereas the metacognitive model includes negative appraisals about worrying (Wells, 2000). The former two models have their roots in Borkovec's avoidance model (Borkovec, Alcaine, \& Behar, 2004), in which worry is considered a maladaptive strategy to suppress emotional arousal by verbal linguistic thoughts, as opposed to imagery. The emotion dysregulation model includes four components, namely, fear of emotions, reduced clarity of emotions, reduced control over emotions, and heightened intensity of emotions. In contrast, the acceptance-based model emphasizes avoidance of inner experiences and reduced action in the valued direction in the etiology of GAD. Despite these differences, a link between fear of emotions and GAD has been reported in several studies (Buhr \& Dugas, 2012; Mennin et al., 2005; Roemer, Salters, Raffa, \& Orsillo, 2005).

In his metacognitive model, Wells (2000) proposed that both positive and negative beliefs about worry work in the development and maintenance of pathological worry and GAD. Positive metacognitive beliefs are about the perceived utility of worry, and are thought to increase worrying about external events, or 
noncognitive inner experiences. Negative metacognitive beliefs represent a view of worrying as uncontrollable and dangerous that can eventually lead to worrying about worrying. There has been strong empirical support for the relationship between negative metacognitive beliefs and GAD, whereas the predictive power of positive beliefs on GAD symptoms is relatively weak (e.g., Hirsch, Mathews, Lequertier, Perman, \& Hayes, 2013; Penney, Mazmanian, \& Rudanycz, 2013).

In the metacognitive model (Wells, 2000), negative views about worry and emotions are expected to function quite differently. Negative beliefs about worrying are generally focused on uncontrollability and the possible harm of worrying, whereas fear of emotions is thought to trigger worry in the first place. Thus we expect negative beliefs about worrying and emotions have an independent relationship to worrying and to GAD symptoms. In addition, negative beliefs about worrying should have much stronger predictive power than fear of emotions, as the former are more directly related to intensified GAD symptoms (Wells, 2006). In contrast, the acceptance-based model (Roemer \& Orsillo, 2002) considers that appraisals of worrying and emotions are subfacets of the overarching construct of experiential avoidance (i.e., aversion and avoidance of negative inner experiences in general). Therefore, it is expected that negative appraisals about worrying and emotions function similarly, and as a result no difference in predictive power is expected between them. In addition, it is expected that experiential avoidance would largely explain the effects of negative metacognitive beliefs and the fear of emotions on worrying. Finally, according to the acceptance-based model, experiential avoidance will be an overarching construct, subsuming both negative metacognitive beliefs and the fear of emotions.

Our first research question concerns the relative predictive power of negative beliefs about worry and the fear of emotions, and their relationship to experiential avoidance. Roemer et al. (2005) found that worry and GAD symptoms (both clinical and non-clinical) were related to fear of anxiety, as well as to experiential avoidance. Buhr \& Dugas (2012) found that the fear of emotions, experiential avoidance, and intolerance of uncertainty, all make independent contributions to non-clinical worry and the degree of GAD symptoms, whereas experiential avoidance exhibits relatively weak predictive power. Stapinski, Abbott, \& Rapee (2010) included the fear of emotions and metacognitive beliefs, with other variables such as intolerance of uncertainty, threat perception, and perceived uncontrollability of emotions in regression models. Their results indicated that metacognitive beliefs, together with threat perception and perceived uncontrollability of emotions predicted the degree of both clinical and non-clinical worrying. However, Stapinski et al. (2010) examined metacognitive beliefs as a total score, and did not specifically use the negative beliefs subscale as a predictor of GAD. To the authors' knowledge, the present study is the first to simultaneously compare the predictive power and directly examine the interelationships of experiential avoidance, negative metacognitive beliefs, and the fear of emotions. In addition, we used structural equation modeling (SEM) to examine whether experiential avoidance may serve as an overarching construct explaining both neg- 
ative metacognitive beliefs and the fear of emotions, or these three predictors are related but independent constructs.

\subsection{Relative Predictive Power of Factors Related to Problem-Solving}

Our second question concerns the role of problem-solving in worrying and GAD. In early scientific research, worry has been considered as an attempt to solve problems (Borkovec, Robinson, Pruzinsky, \& DePree, 1983). Such a view is reflected in items used to measure positive metacognitive beliefs about worrying (e.g., "Worrying helps me to solve problems"; Wells \& Cartwright-Hatton, 2004) and intolerance of uncertainty (e.g., "I should be able to organize everything in advance"; Freeston, Rheaume, Letarte, Dugas, \& Ladouceur, 1994). In addition, negative problem orientation, which includes dysfunctional attitudes toward social problem-solving (e.g., low confidence in problem-solving), is known to be related to GAD (e.g., Dugas et al., 2007). Finally, a recent initiation-termination (IT) model of worrying (Berenbaum, 2010), which aims to integrate many of the proposed predictors of worrying, includes components related to problemsolving. For example, delay or failure to engage in active problem-solving prevents the termination of worrying, whereas goal investment is thought to lead to the initiation of worrying. Pomenrantz, Saxon, and Oishi (2000) found that goal investment and perceived effort for goals are related to worrying, as well as positive emotions.

However, the relative importance of problem-solving compared to the aversion of inner experiences, which is a process featured in many models (Behar et al., 2009), needs further elucidation. For example, in the avoidance model of Borkovec, Shadick, \& Hopkins (1991), which emphasized the avoidance of emotional arousal by worry, "worry as problem-solving" was viewed as a post-hoc attribution made by worriers. In his IT model, Berenbaum (2010) predicted that disinclination to solve problems mediates the effect of experiential avoidance and reduced emotional clarity on worry. Therefore, the relative predictive power of the factors related to problem-solving awaits empirical investigation.

It is important to consider how to operationalize aspects of problem-solving most conducive to worrying. As noted above, problem-solving is reflected in multiple worry-related constructs, yet there are differences in the predictive power of different variables. For example, whereas the intolerance of uncertainty is a strong predictor (e.g., Dugas et al., 2007) of GAD, there is limited support for the predictive power of positive beliefs about worrying (Wells, 2006), although in adolescents Thielsch, Andor, \& Ehring (2015) found both positive and negative metacognitions predicted scores on the Penn State Worry Questionnaire (PSWQ), along with intolerance of uncertainty. A relatively new construct called responsibility to continue thinking (RESP; Sugiura, 2007; Sugiura, Sugiura, \& Tanno, 2013), which is the belief that one needs to engage in prolonged thinking about stressful problems, offers a promising candidate for our research. 
First, RESP focuses explicitly on problem-solving such that items are rated with reference to the time that respondents are engaged in solving difficult problems. Secondly, RESP seems to capture some aspects of the IT model of worrying (Berenbaum, 2010), which places importance on the lack of a sense of closure (i.e., satisfaction that one has resorted to all the necessary means) and perseverative iterative style (i.e., tendency to repeat and continue a given chain of thoughts) in determining delayed termination of worry, and goal investment in the initiation of worrying, together with other factors. RESP items seem to reflect a reduced sense of closure (e.g., "I somehow feel that I have not thought enough about the problem, and I need to think through."), perseverative iterative style (e.g., "I have to keep thinking about this problem over and over."), and possibly goal investment (e.g., "I will make every effort to improve this situation."). Sugiura, Sugiura, \& Tanno (2013) reported its incremental prediction over metacognitive beliefs. Sugiura (2007) demonstrated the incremental validity of RESP in predicting worrying over and above many other predictors (neuroticism, intolerance of uncertainty, positive/negative metacognitive beliefs, poor problemsolving orientation, and cognitive avoidance). Nonetheless, because RESP is a relatively novel concept, evidence of its unique predictive power relative to aversion of inner experiences is required. However, to date, comparison of RESP with fear of emotions and experiential avoidance has not been conducted.

\subsection{Aims of the Present Study}

In the present study, we addressed two questions regarding the relative predictive power of multiple model factors. First, we compared factors reflecting a negative view of inner experiences. Two competing predictions are possible. 1) Negative metacognitive beliefs will have a stronger effect on GAD symptoms and worry than fear of emotions. 2) Experiential avoidance will explain the effect of negative metacognitive beliefs and the fear of emotions on GAD symptoms and worry. In addition we used SEM to examine two additional competing predictions: 3) Experiential avoidance serves as an overarching construct explaining both negative metacognitive beliefs and the fear of emotions. 4) The three predictors are related but independent constructs.

Second, we compared RESP to models related to an aversion of inner experiences. As this is the first study that includes RESP, the fear of emotions, and experiential avoidance, it remains unknown whether RESP has independent predictive power among the present set of predictors.

Study 1 compared fear of anxiety, negative beliefs about worrying, and RESP, in which both worrying and GAD symptoms served as dependent variables. Although we focused on the prediction of dimensional GAD symptom severity, discriminant function analysis (DFA) was also conducted as a supplementary analysis in Study 1 to predict dichotomous GAD status by self-report measures. DFA yields linear combination of predictors to produce maximum discrimination of target groups. Predictors having high correlations with discriminant 
functions are considered to contribute to the classification.

Study 2 included experiential avoidance. In addition, neuroticism was also measured because studies have repeatedly demonstrated its relation to worry (e.g., Sexton, Norton, Walker, \& Norton, 2003). Study 2 also included the fear of a wider range of emotions, although only worrying served as the dependent variable. In addition, Study 2 conducted SEM to investigate interrelationships among experiential avoidance, negative metacognitive beliefs, and the fear of emotions.

\section{Study 1}

\subsection{Method}

\subsubsection{Participants}

Japanese college students ( $N=390$; mean age 19.39 years, $S D=3.46$; $48 \%$ women) completed questionnaires during class in exchange for partial course credit. The study was approved by the institutional ethical review board. The nature and purpose of the study were explained to the participants. They were free to refuse participation in the study and they completed the questionnaires only if they agreed to participate in the study.

\subsubsection{Instruments}

The Penn State Worry Questionnaire (PSWQ; Meyer, Miller, Metzger, \& Borkovec, 1990) is a 16-item questionnaire (5-point scale). It has excellent psychometric properties to measure the frequency and intensity of pathological worry. The Japanese version of the scale (Sugiura \& Tanno, 2000) has psychometric properties comparable to those of the original version (Startup \& Erickson, 2006). In a student sample these properties included good internal consistency ( $\alpha=0.92$ ), positive correlations with anxiety and depression, and the ability to discriminate between worry and obsessive symptoms. The Generalized Anxiety Disorder Questionnaire-IV (GADQ-IV; Newman et al., 2002) measures GAD symptoms defined by DSM-IV criteria. It can be used to compute dimensional symptom severity, and it can also yield dichotomous GAD status. Dimensional scores were used here. The original version of the GADQ-IV asks participants to skip questions about physical symptoms and distress if one has not been bothered by excessive and uncontrollable worry on more days than not, during the last six months. This specification was removed here to focus on the continuous distribution of GAD symptoms (following the practice of Roemer, Lee, SaltersPedneault, Erisman, Mennin, \& Orsillo, 2009). The Japanese version of this scale developed by Takebayashi, Takagaki, \& Sugiura (2012) has good reliability ( $\alpha=$ 0.85 ; test-retest ICC $=0.73$ ) and convergent validity (correlation with worrying, trait anxiety, and intolerance of uncertainty) as compared with the original version, in addition to a one-factor structure. Based on the original cutoff score of $5.7,34 \%$ of 322 college students were classified as possible candidates for GAD (Takebayashi et al., 2012). This proportion is similar to previous reports (e.g., $33 \%$ in Turk, Heimberg, Luterek, Mennin, \& Fresco, 2005), supporting the va- 
lidity of dichotomous classification using this measure.

The Meta-Cognitions Questionnaire short form (MCQ-30; Wells \& CartwrightHatton, 2004), which contains 30 -item rated on a four-point scale, measures beliefs about worry and intrusive thoughts. The MCQ-30 has established psychometric properties including its relationship to worrying. Sugiura, Sugiura, \& Umaoka (2003) translated the 65-item full version of the MCQ (CartwrightHatton \& Wells, 1997) into Japanese and confirmed the good reliability of each subscale ( $\alpha=0.83-0.89$ ). Of the five subscales, the negative metacognitive beliefs subscale was used (6 items used in MCQ-30), with good reliability in both studies $(\alpha=0.86)$.

The RESP (Sugiura, 2005, 2007) reflects beliefs about the need for prolonged thinking about stressful problems. In this scale, participants rate 14 items on a 5-point scale, as to how often they occurred while they were solving stressful problems. Sugiura (2005) reported adequate reliability ( $\alpha$ s $>0.88$ ) and validity of this measure, including its positive correlation with perfectionism and active problem-solving.

The Affective Control Scale (ACS; Williams, Chambless, \& Ahrens, 1997) measures negative appraisals of four emotions, namely, fear, depression, anger, and positive emotions. It has 42 items, each rated on a seven-point scale. The Japanese version has acceptable to good internal consistency and correlates with indices of maladaptive emotional regulation, such as reduced emotional clarity and avoidance of negative emotions (Kanetsuki, Kanetsuki, \& Oikawa, 2010). Only the fear of anxiety subscale was used in Study 1 on the basis that of the subscales, fear of anxiety was most strongly related to GAD status/symptoms (Buhr \& Dugas, 2012; Mennin et al., 2005; Roemer et al., 2005).

\subsubsection{Statistical Analyses}

A stepwise regression analysis was conducted to examine relative predictive power of etiological factors on worrying and GAD symptoms. In addition, DFA was used to examine their power to predict dichotomous GAD status.

\subsection{Results and Discussion}

As shown in Table 1 , all scales had good to excellent reliability ( $\alpha=0.82-0.92)$. As expected, negative evaluations of worrying (MCQ negative beliefs) and anxiety (ACS anxiety) were positively correlated $(r=0.52 ; p<0.001)$.

All predictors were positively correlated with the PSWQ and the GAD-Q-IV (see Table 1). Because this study postulated multiple possibilities regarding the relative predictive power of variables in the model, rather than on the incremental validity of one particular variable over others, we conducted stepwise regression analyses, as shown in Table 2. Given the relatively large sample size, a significance level of $1 \%$ (two-tailed) was used in the two studies. A variance inflation factor (VIF) greater than 1.78 was not observed, suggesting no multicollinearity (VIF $>10$ is usually considered to represent a risk of multicollinearity). All three predictors (MCQ negative beliefs, ACS anxiety, and RESP) remained 
Table 1. Descriptive statistics and correlation of study 1 variables $(N=390)$.

\begin{tabular}{|c|c|c|c|c|c|c|}
\hline & & (1) & (2) & (3) & (4) & (5) \\
\hline (1) & MCQ-Negative Beliefs & 1.00 & 0.52 & 0.34 & 0.75 & 0.69 \\
\hline (2) & ACS anxiety & & 1.00 & 0.20 & 0.62 & 0.61 \\
\hline (3) & RESP & & 0.20 & 1.00 & 0.42 & 0.37 \\
\hline (4) & PSWQ & & & & 1.00 & 0.74 \\
\hline \multirow[t]{4}{*}{ (5) } & GADQ-IV & & & & & 1.00 \\
\hline & $M$ & 11.93 & 21.78 & 46.85 & 49.24 & 4.08 \\
\hline & $S D$ & 4.10 & 7.74 & 9.60 & 12.21 & 2.70 \\
\hline & $\alpha$ & 0.86 & 0.82 & 0.87 & 0.92 & 0.83 \\
\hline
\end{tabular}

Note. $\mathrm{MCQ}=$ Meta-Cognitions Questionnaire short form; ACS = Affective Control Scale; RESP = Responsibility to continue thinking; PSWQ = Penn State Worry Questionnaire; GADQ-IV = Generalized Anxiety Disorder Questionnaire-IV. $r s>0.20$ are significant at $p<0.001$.

Table 2. Stepwise regression analyses predicting worry (PSWQ) and GAD symptoms (GADQ-IV) $(N=390)$.

\begin{tabular}{ccc}
\hline & Worry & GAD Symptoms \\
\cline { 2 - 3 } Predictors & $\beta$ & $\beta$ \\
\hline MCQ-Negative Beliefs & $0.53^{* * *}$ & $0.45^{* * *}$ \\
ACS anxiety & $0.26^{* * *}$ & $0.30^{* * *}$ \\
RESP & $0.19^{* * *}$ & $0.15^{* * *}$ \\
$R^{2}$ & $0.63^{* * *}$ & $0.55^{* * *}$ \\
\hline
\end{tabular}

Note. PSWQ = Penn State Worry Questionnaire; GADQ-IV = Generalized Anxiety Disorder Questionnaire-IV; MCQ = Meta-Cognitions Questionnaire short form; ACS = Affective Control Scale; RESP = Responsibility to continue thinking. ${ }^{* * *} p<0.001$.

significant in predicting both the PSWQ and the GADQ-IV, explaining 63\% and $55 \%$ of the variance, respectively. In both cases, negative metacognitive beliefs were associated with the largest beta $(\beta=0.53$ and $0.45 ; p<0.001)$.

Prediction of GAD diagnostic status based on GADQ-IV (cutoff score of 5.7) was also conducted with the same set of three predictors. Using this cutoff point, $26 \%$ (102 of 390 participants) were classified as potentially exhibiting GAD. The discriminant function was significant (Wilk's $\lambda=0.66$; $p<0.001$ ), correctly classifying $59.8 \%$ of participants with GAD and $93.1 \%$ of participants without GAD. Negative beliefs about worrying was most strongly related to the discriminant function $(r=0.95)$, followed by fear of anxiety $(r=0.67)$, and the RESP $(r=$ $0.42)$.

Both negative beliefs about worrying and emotions had independent predictive power regarding worry and dimensional GAD symptoms, with the former acting as a better predictor. This is the first direct comparison of these two negative beliefs about inner experiences and is consistent with the prediction from the metacogitive model. In addition, the RESP indicated independent predictive 
power over not only negative metacognitive beliefs, but also fear of anxiety. In addition, all three predictors were related to discrimination of GAD diagnosis via the GADQ-IV, whereas negative metacognitive beliefs had the strongest relationship to the discriminant function. However, a caveat here is the relatively high false negative rate in the DFA ( $40.2 \%$ of GAD candidates according to GADQ-IV were classified as non-GAD). However, this may be explicable on the basis that the present study employed a non-clinical sample.

\section{Study 2}

\subsection{Method}

\subsubsection{Participants}

Japanese college students ( $N=371$; mean age 18.78 years, $S D=2.17$; $57 \%$ women) completed questionnaires during class. The same procedure as Study 1 was followed, including ethical considerations.

\subsubsection{Instruments}

In Study 2, MCQ-30 negative metacognitive beliefs were used as in Study 1. The ACS was used in its full form, including the four subscales for the fear of different emotions. Measure of experiential avoidance and neuroticism were added. Only the PSWQ scores served as a dependent variable.

The Acceptance and Action Questionnaire (AAQ; Bond \& Bunce, 2003) is a self-report measure designed to assess experiential avoidance. Matsumoto \& Ohkouti (2012) translated the measure, conducted factor analysis, and retained 10 items ( 5 items for openness toward internal experience and 5 items for ability to take action even in the face of difficulty). Items were rated on a seven-point scale, with higher scores indicating the presence of higher levels of experiential avoidance. Both subscales of the Japanese AAQ demonstrated a relationship to avoidant coping, thought suppression, rumination, anxiety, depression, and general health. The total score was used as the measure of interest in this study. Internal consistency in the present sample was low to adequate $(\alpha=0.60)$. Therefore, these results should be interpreted with caution.

Neuroticism was measured using the Big Five Scale (BFS; Wada, 1996). Each of the Big Five factors contains 12 trait adjectives, each rated on a seven-point scale. All subscales showed good to excellent internal consistency ( $\alpha s>0.84$ ), as well as content and factorial validity. The neuroticism subscale contains items such as nervous, feelings easily upset, and tense.

\subsubsection{Statistical Analyses}

A stepwise regression analysis was conducted to examine relative predictive power of etiological factors on worrying. In addition, SEM was used to investigate interrelationships among experiential avoidance, negative metacognitive beliefs, and the fear of emotions.

\subsection{Results and Discussion}

As shown in Table 3, all scales, with the exception of the AAQ, evidenced good 
reliability ( $\alpha s=0.81-0.93$ ). While alpha for the AAQ was not good, as its relations to other measures were understandable, we retained in the following analyses.

All predictors were positively correlated with worrying (see Table 3). As Table 4 depicts, a stepwise regression analysis predicting the PSWQ was conducted. A VIF greater than 2.47 was not observed, suggesting no multicollinearity. All predictors remained significant, with the exception of experiential avoidance, with $79 \%$ of the variance explained. Of all the predictors, neuroticism had the largest beta $(\beta=0.45 ; p<0.001)$, followed by negative metacognitive beliefs $(\beta=0.33 ; p<0.001)$.

To investigate the interrelationships among negative appraisals about emotions, those about worry, and experiential avoidance, structural equation modeling was conducted. Three latent variables were introduced: experiential avoidance, fear of emotions, and negative beliefs about worrying. Fear of emotions was measured by the four ACS subscales. Because negative beliefs is a single

Table 3. Descriptive statistics and correlation of study 2 variables $(N=371)$.

\begin{tabular}{ccccccc}
\hline & $(1)$ & $(2)$ & $(3)$ & $(4)$ & $(5)$ & $(6)$ \\
\hline Neuroticism & 1.00 & 0.67 & 0.72 & 0.47 & 0.45 & 0.82 \\
MCQ-Negative Beliefs & & 1.00 & 0.68 & 0.53 & 0.44 & 0.78 \\
ACS total & & & 1.00 & 0.49 & 0.53 & 0.74 \\
RESP & & & & 1.00 & 0.16 & 0.55 \\
AAQ & & & & & 1.00 & 0.45 \\
PSWQ & 55.46 & 11.94 & 13.15 & 42.44 & 42.46 & 49.34 \\
$M$ & 12.92 & 4.32 & 4.27 & 9.65 & 6.32 & 12.51 \\
$S D$ & 0.91 & 0.86 & 0.81 & 0.87 & 0.60 & 0.93 \\
\hline
\end{tabular}

Note. MCQ = Meta-Cognitions Questionnaire short form; ACS = Affective Control Scale; RESP = Responsibility to continue thinking; ACS = Affective Control Scale; RESP = Responsibility to continue thinking; $\mathrm{AAQ}=$ Acceptance and Action Questionnaire; PSWQ $=$ Penn State Worry Questionnaire. $r s>0.16$ are significant at $p<0.01 ; r s>0.24$ are significant at $p<0.001$.

Table 4. Stepwise regression analysis predicting worry (PSWQ) $(N=371)$.

\begin{tabular}{cc}
\hline Predictors & $\beta$ \\
Neuroticism & $0.45^{\star * *}$ \\
MCQ-Negative Beliefs & $0.33^{\star * *}$ \\
ACS total & $0.15^{\star * *}$ \\
RESP & $0.09^{\star *}$ \\
$R^{2}$ & $0.79^{* * *}$
\end{tabular}

Note. PSWQ = Penn State Worry Questionnaire; MCQ = Meta-Cognitions Questionnaire short form; ACS $=$ Affective Control Scale; RESP $=$ Responsibility to continue thinking. ${ }^{* *} p<0.01 ;{ }^{* * *} p<0.001$. 
subscale, items were alternately divided into two parcels (Little, Cunningham, Shahar, \& Widaman, 2002). In addition, although experiential avoidance has two subscales, as their correlation was too small $(r=0.09 ; p<10)$, we used the total AAQ score as a single manifest variable for the construct. The error variance term of the AAQ was fixed, computed based on alpha reliability.

Two alternative models were compared. In the first, experiential avoidance was the overarching construct predicting both fear of emotions and negative beliefs about worrying. In the second, the three variables were related but independent constructs. Table 5 depicts fit indices for two models. The root mean square error of approximation (RMSEA) was smaller for the related but independent model, but its value of 0.12 suggests that even this model did not fit the data well. However, because our focus was the relative performance of the two models, we note that the comparative and non-normed fit indices were lower, and RMSEA higher, for the model using experiential avoidance as the overarching construct. The Akaike and Bayes information criteria are specialized indices for model comparison. Both indicated better fit for the related but independent constructs model. Therefore, fear of emotions and negative beliefs about worrying cannot be considered a subfacet of experiential avoidance.

Study 2 replicated Study 1 in showing independent predictions by both negative metacognitive beliefs and fear of emotions, with strong predictive power of the former. Furthermore, experiential avoidance did not account for the effect of negative metacognitive beliefs, fear of emotions on worry. In addition, experiential avoidance, negative metacognitive beliefs, and the fear of emotions were related but independent constructs, that is experiential avoidance was not an overarching construct explaining the other two constructs in SEM. These results are inconsistent with the acceptance-based model, which considers the negative view of worry and emotions as subfacets of experiential avoidance. In contrast, the results lend further support to the metacognitive model, as negative metacognitive beliefs evidenced the second strongest predictive power with respect to worrying. Independent predictive power of RESP was also shown over other predictors including neuroticism and experiential avoidance.

\section{General Discussion}

The first aim of this study was to examine whether multiple scales related to the aversion of inner experiences predicted GAD symptoms. Results indicated that

Table 5. Fit indices for two alternative models of the interrelation of three construct related to negative reactions to inner experiences.

\begin{tabular}{cccccc}
\hline Models & CFI & NNFI & RMSEA & AIC & BIC \\
\hline $\begin{array}{c}\text { Experiential avoidance as } \\
\text { overarching construct }\end{array}$ & 0.94 & 0.90 & 0.15 & 148.66 & 207.40 \\
$\begin{array}{c}\text { Related but independent construct } \\
\text { Ren }\end{array}$ & 0.96 & 0.93 & 0.12 & 107.75 & 170.41 \\
\hline
\end{tabular}

Note CFI = comparative fit index; NNFI = nonnormed fit index; RMSEA = root mean square error of approximation; AIC = Akaike Information criterion; $\mathrm{BIC}=$ Bayes information criterion. 
both negative appraisals about emotions and worrying exerted independent predictive power over each other, as well as over neuroticism and experiential avoidance. Negative metacognitive beliefs about worrying had a stronger influence on worrying and GAD than the fear of emotions. Consistent findings also emerged from a DFA, where negative metacognitive beliefs were most strongly related to the discriminant function, followed by fear of anxiety. In addition, we examined whether negative appraisals about worrying and emotions can be conceptualized as subfacets of experiential avoidance. SEM results indicated that these two kinds of beliefs cannot be considered simply as facets of aversion of negative inner experience. These findings are consistent with the metacognitive model, which considers negative metacognitive beliefs to be a proximal contributory cause in the pathway leading to the development of GAD (Wells, 2006). However, strong inferences about temporal proximity await longitudinal examination.

Although Stapinski et al. (2010) measured both metacognitive beliefs and fear of emotions, the investigators did not conduct a subscale-level analysis, and therefore did not focus directly on negative beliefs about worrying. Therefore, to our knowledge, our study represents the first direct comparison of negative metacognitive beliefs, including fear of emotions and experiential avoidance. The present results suggest that negative beliefs about worrying require a particular focus and should not be simply considered as one of the manifestations of experiential avoidance. The independent predictive power evidenced by fear of emotions suggests that this variable might also be targeted in treatment.

Experiential avoidance did not evidence incremental validity in the prediction of worrying. Evidence is mixed regarding its predictive power. Kashdan, Barrios, Forsyth, \& Steger (2006) found that experiential avoidance mediated the effect of emotional regulation on anxiety, whereas Kollman, Brown, \& Barlow (2009) failed to find a relationship between acceptance (reduced experiential avoidance) and worry/social anxiety. Buhr \& Dugas (2012) found that experimental avoidance exhibited weak predictive power relative to fear of anxiety and intolerance of uncertainty. This finding led Buhr \& Dugas (2012) to speculate that experiential avoidance is a generalized vulnerability factor, as opposed to a GAD-specific factor. However, in the present results, experiential avoidance did not serve as a superfactor of negative appraisals about inner experiences. The relatively low alpha reliability of the AAQ might have compromised its predictive value. Future studies should consider the AAQ-II (Bond et al., 2011), which overcomes the internal consistency problems.

Regarding the second question concerning the role of problem-solving in worrying and GAD, we compared responsibility to continue thinking to models related to an aversion of inner experiences. The incremental validity of the RESP was demonstrated. RESP was also related to the discriminant function predicting GAD status, albeit to a lesser degree than negative metacognitive beliefs and fear of anxiety. This suggests problem-solving is still important in worrying and $\mathrm{GAD}$, although many current models emphasize a relationship to inner expe- 
riences (Behar et al., 2009). Buhr \& Dugas (2012) considered that the approach-avoidance dilemma in GAD was reflected in their finding of independent predictions by both intolerance of uncertainty and fear of emotions. Wells (1995) noted metacognitive dissonance arising from the coexistence of both positive and negative beliefs about worrying. The present findings are also consistent with such a dilemma. RESP includes continuing problem-solving related thoughts, and seems to reflect some components of the initiation-termination model (Berenbaum, 2010), namely, a sense of closure, perseverative-iterative style, and goal investment, rendering indirect support for the model. That is, worrying is thought to reflect continued thinking about problems with perceived insufficiency. The importance of continued thinking is understandable in light of the notion that the cardinal features of pathological worry are perseverance (Brosschot, Gerin, \& Thayer, 2006; Ruscio, Seitchik, Gentes, Jones, \& Hallion, 2011). Finally, neuroticism evidenced strong predictive power for worrying in Study 2, which is consistent with prior findings (Sexton et al., 2003).

The present study suggests that research and practice should focus on more specific factors (e.g., negative beliefs about worrying), rather than on a general umbrella construct (e.g., experiential avoidance). Considering recent findings of a lack of augmentation of CBT by emotion processing techniques (Newman et al., 2011), the present approach of searching for stronger predictors among specific candidate variables is recommended, rather than talking simply about “cognitions" or "emotions".

A first limitation of the present study is the reliance on a non-clinical population, which may not generalize to those clinically diagnosed with GAD. However, inclusion of a relatively large number of participants, and the use of the GADQ-IV in addition to the PSWQ, are strengths of this study, and there are evidence of continuity in the distribution of worry (Olatunji, Broman-Fulks, Bergman, Green, \& Zlomke, 2012). A second limitation is that only self-report measures were used. Third, temporal relationships among process variables remain unclear when using cross-sectional data. Future longitudinal studies are required in order to examine the mechanisms underlying the relationship among predictors and GAD. Fourth, future studies should examine how fear of emotions leads to GAD psychopathology. Llera \& Newman (2014) and Newman \& Llera (2011) proposed that worry does not suppress emotional arousal, but rather enables individuals to avoid the experience of unexpected worsening of emotions by prolonging negative emotions. This model suggests reasons why people fearful of emotions may worry, and warrants further investigation. Fifth, while our Study 1 focused on fear of anxiety, and Study 2 included fear of four emotions, recent studies have found a role of fear of shame (Schoenleber, Chow, \& Berenbaum, 2014) and anger (Fracalanza, Koerner, Deschenes, \& Dugas, 2014) in GAD. Therefore, beliefs regarding a variety of emotions should be taken into account, together with a fear of a sharp increase of the intensity of emotions, in addition to reactions to emotions themselves (Llera \& Newman, 2012). Sixth, studies involving clinical samples in a therapeutic context are necessary. 
For example, metacognitive therapy first targets negative beliefs then proceeds to positive beliefs, which is thought to motivate worrying (Wells, 2000). A reduced fear of emotions may reduce over-reliance on worrying, and reduced responsibility may reduce the motivation to continue worrying. Therefore, these variables may be altered following treatment that targets the modification of negative beliefs. Finally, future studies should also examine the interaction between beliefs about problem-solving and actual problem-solving ability. Penney, Miedema, \& Mazmanian (2015) found verbal intelligence was positively related to worrying, and Gentes \& Ruscio (2014) perceived performance impairments are due to elevated performance standards.

\section{Acknowledgements}

This study was supported by a JSPS Grant-in-Aid for Scientific Research (C) (No: 26380929). There are no conflicts of interests to declare.

\section{References}

Andrews, G., Hobbs, M. J., Borkovec, T. D., Beesdo, K., \& Craske, M. G. (2010). Generalized Worry Disorder: A Review of DSM-IV Generalized Anxiety Disorder and Options for DSM-V. Depression and Anxiety, 27, 134-147.

https://doi.org/10.1002/da.20658

Behar, E., DiMarco, I. D., Heckler, E. B., Mohlman, J., \& Staples, A. M. (2009). Current Theoretical Models of Generalized Anxiety Disorder (GAD): Conceptual Review and Treatment Implications. Journal of Anxiety Disorders, 23, 1011-1023.

https://doi.org/10.1016/j.janxdis.2009.07.006

Berenbaum, H. (2010). An Initiation-Termination Two-Phase Model of Worrying. Clinical Psychology Review, 30, 962-975. https://doi.org/10.1016/j.cpr.2010.06.011

Bond, F. W. \& Bunce, D. (2003). The Role of Acceptance and Job Control in Mental Health, Job Satisfaction, and Work Performance. Journal of Applied Psychology, 88, 1057-1067. https://doi.org/10.1037/0021-9010.88.6.1057

Bond, F. W., Hayes, S. C., Baer, R. A., Carpenter, K. M., Guenole, N., Orcutt, H. K., Zettle, R. D. et al. (2011). Preliminary Psychometric Properties of the Acceptance and Action Questionnaire-II: A Revised Measure of Psychological Inflexibility and Experiential Avoidance. Behavior Therapy, 42, 676-688.

https://doi.org/10.1016/j.beth.2011.03.007

Borkovec, T. D., Alcaine, O., \& Behar, E. (2004). Avoidance Theory of Worry and Generalized Anxiety Disorder. In R. G. Heimberg, C. L. Turk, \& D. S. Mennin (Eds.), Generalized Anxiety Disorder: Advances in Research and Practice (pp. 77-108). New York: Guilford Press.

Borkovec, T. D., Robinson, E., Pruzinsky, T., \& DePree, J. A. (1983). Preliminary Exploration of Worry: Some Characteristics and Processes. Behaviour Research and Therapy, 21, 9-16. https://doi.org/10.1016/0005-7967(83)90121-3

Borkovec, T. D., Shadick, R. N., \& Hopkins, M. (1991). The Nature of Normal and Pathological Worry. In R. M. Rapee, \& D. H. Barlow (Eds.) Chronic Anxiety: Generalized Anxiety Disorder and Mixed Anxiety-Depression (pp. 29-51). New York: Guilford.

Brosschot, J. F., Gerin, W., \& Thayer, J. F. (2006). The Perseverative Cognition Hypothesis: A Review of Worry, Prolonged Stress-Related Physiological Activation, and Health. Journal of Psychosomatic Research, 60, 113-124. 
https://doi.org/10.1016/j.jpsychores.2005.06.074

Buhr, K., \& Dugas, M. J. (2012). Fear of Emotions, Experiential Avoidance, and Intolerance of Uncertainty in Worry and Generalized Anxiety Disorder. International Journal of Cognitive Therapy, 5, 1-17. https://doi.org/10.1521/ijct.2012.5.1.1

Cartwright-Hatton, S., \& Wells, A. (1997). Beliefs about Worry and Intrusions: The MetaCognitions Questionnaire and Its Correlates. Journal of Anxiety Disorders, 11, 279296. https://doi.org/10.1016/S0887-6185(97)00011-X

Cuijpers, P., Sijbrandij, M., Koole, S., Huibers, M., Berking, M., \& Andersson, G. (2014). Psychological Treatment of Generalized Anxiety Disorder: A Meta-Analysis. Clinical Psychology Review, 34, 130-140. https://doi.org/10.1016/j.cpr.2014.01.002

Dugas, M. J., Savard, P., Gaudet, A., Turcotte, J., Laugesen, N., Robichaud, M., Koener, N. et al. (2007). Can the Components of a Cognitive Model Predict the Severity of Generalized Anxiety Disorder? Behavior Therapy, 38, 169-178.

https://doi.org/10.1016/j.beth.2006.07.002

Fracalanza, K., Koerner, N., Deschenes, S. S., \& Dugas, M. J. (2014). Intolerance of Uncertainty Mediates the Relation between Generalized Anxiety Disorder Symptoms and Anger. Cognitive Behaviour Therapy, 43, 122-132.

https://doi.org/10.1080/16506073.2014.888754

Freeston, M., Rheaume, J., Letarte, H., Dugas, M. J., \& Ladouceur, R. (1994). Why Do People Worry? Personality and Individual Differences, 17, 791-802.

https://doi.org/10.1016/0191-8869(94)90048-5

Gentes, E. L., \& Ruscio, A. M. (2014). Perceptions of Functioning in Worry and Generalized Anxiety Disorder. Cognitive Therapy and Research, 38, 518-529.

https://doi.org/10.1007/s10608-014-9618-8

Hanrahan, F., Field, A. P., Jones, F. W., \& Davey, G. C. (2013). A Meta-Analysis of Cognitive Therapy for Worry in Generalized Anxiety Disorder. Clinical Psychology Review, 33, 120-132. https://doi.org/10.1016/j.cpr.2012.10.008

Hirsch, C. R., Mathews, A., Lequertier, B., Perman, G., \& Hayes, S. (2013). Characteristics of Worry in Generalized Anxiety Disorder. Journal of Behavior Therapy and Experimental Psychiatry, 44, 388-395. https://doi.org/10.1016/j.jbtep.2013.03.004

Kanetsuki, M., Kanetsuki, T., \& Oikawa, M. (2010). The Relationship between Fear of Emotions and Stress Responses: Development of the Japanese-Version Affective Control Scale. The Japanese Journal of Research on Emotions, 18, 42-50. https://doi.org/10.4092/jsre.18.42

Kashdan, T. B., Barrios, V., Forsyth, J. P., \& Steger, M. F. (2006). Experiential Avoidance as a Generalized Psychological Vulnerability: Comparisons with Coping and Emotion Regulation Strategies. Behaviour Research and Therapy, 44, 1301-1320. https://doi.org/10.1016/j.brat.2005.10.003

Kollman, D. M., Brown, T. A., \& Barlow, D. H. (2009). The Construct Validity of Acceptance: A Multitrait-Multimethod Investigation. Behavior Therapy, 40, 205-218. https://doi.org/10.1016/j.beth.2008.06.002

Little, T. D., Cunningham, W. A., Shahar, G., \& Widaman, K. F. (2002). To Parcel or Not to Parcel: Exploring the Question, Weighing the Merits. Structural Equation Modeling, 9, 151-173. https://doi.org/10.1207/S15328007SEM0902_1

Llera, S. J., \& Newman, M. G. (2014). Rethinking the Role of Worry in Generalized Anxiety Disorder: Evidence Supporting a Model of Emotional Contrast Avoidance. Behavior Therapy, 45, 283-299. https://doi.org/10.1016/j.beth.2013.12.011

Matsumoto, A., \& Okouchi, H. (2012). Development of the Acceptance and Action Questionnaire for Japanese Version. Behavioral Science Research, 50, 75-84. 
Mennin, D. S., Heimberg, R. G., Turk, C. L., \& Fresco, D. M. (2005). Preliminary Evidence for an Emotion Dysregulation Model of Generalized Anxiety Disorder. Behaviour Research and Therapy, 43, 1281-1310. https://doi.org/10.1016/j.brat.2004.08.008

Meyer, T. J., Miller, M. L., Metzger, R. L., \& Borkovec, T. D. (1990). Development and Validation of the Penn State Worry Questionnaire. Behaviour Research and Therapy, 28, 487-495. https://doi.org/10.1016/0005-7967(90)90135-6

Newman, M. G., Castonguay, L. G., Borkovec, T. D., Fisher, A. J., Boswell, J. F., Szkodny, L. E., \& Nordberg, S. S. (2011). A Randomized Controlled Trial of Cognitive-Behavioral Therapy for Generalized Anxiety Disorder with Integrated Techniques from Emotion-Focused and Interpersonal Therapies. Journal of Consulting and Clinical Psychology, 79, 171-181. https://doi.org/10.1037/a0022489

Newman, M. G., \& Fisher, A. J. (2013). Mediated Moderation in Combined Cognitive Behavioral Therapy versus Component Treatments for Generalized Anxiety Disorder. Journal of Consulting and Clinical Psychology, 81, 405-414. https://doi.org/10.1037/a0031690

Newman, M. G., \& Llera, S. J. (2011). A Novel Theory of Experiential Avoidance in Generalized Anxiety Disorder: A Review and Synthesis of Research Supporting a Contrast Avoidance Model of Worry. Clinical Psychology Review, 31, 371-382. https://doi.org/10.1016/j.cpr.2011.01.008

Newman, M. G., Zuellig, A. R., Kachin, K. E., Constantino, M. J., Przeworski, A., Erickson, T., \& Cashman-McGrath, L. (2002). Preliminary Reliability and Validity of the Generalized Anxiety Disorder Questionnaire-IV: A Revised Self-Report Diagnostic Measure of Generalized Anxiety Disorder. Behavior Therapy, 33, 215-233. https://doi.org/10.1016/S0005-7894(02)80026-0

Olatunji, B. O., Broman-Fulks, J. J., Bergman, S. M., Green, B. A., \& Zlomke, K. R. (2012). A Taxometric Investigation of the Latent Structure of Worry: Dimensionality and Associations with Depression, Anxiety, and Stress. Behavior Therapy, 41, 212-228. https://doi.org/10.1016/j.beth.2009.03.001

Penney, A. M., Mazmanian, D., \& Rudanycz, C. (2013). Comparing Positive and Negative Beliefs about Worry in Predicting Generalized Anxiety Disorder Symptoms. Canadian Journal of Behavioural Science/Revue Canadienne des Sciences du Comportement, 45, 34-41. https://doi.org/10.1037/a0027623

Penney, A. M., Miedema, V. C., \& Mazmanian, D. (2015). Intelligence and Emotional Disorders: Is the Worrying and Ruminating Mind a More Intelligent Mind? Personality and Individual Differences, 74, 90-93. https://doi.org/10.1016/j.paid.2014.10.005

Roemer, L., Lee, J., Salters-Pedneault, K., Erisman, S., Mennin, D. S., \& Orsillo, S. M. (2009). Mindfulness and Emotion Regulation Difficulties in Generalized Anxiety Disorder: Preliminary Evidence for Independent and Overlapping Contributions. Behavior Therapy, 40, 142-154. https://doi.org/10.1016/j.beth.2008.04.001

Roemer, L., \& Orsillo, S. M. (2002). Expanding Our Conceptualization of and Treatment for Generalized Anxiety Disorder: Integrating Mindfulness/Acceptance-Based Approaches with Existing Cognitive Behavioral Models. Clinical Psychology: Science and Practice, 9, 54-68. https://doi.org/10.1093/clipsy.9.1.54

Roemer, L., Salters, K., Raffa, S., \& Orsillo, S. M. (2005). Fear and Avoidance of Internal Experiences in GAD: Preliminary Tests of a Conceptual Model. Cognitive Therapy and Research, 29, 71-88. https://doi.org/10.1007/s10608-005-1650-2

Ruggiero, G. M., Stapinski, L., Caselli, G., Fiore, F., Gallucci, M., Sassaroli, S., \& Rapee, R. M. (2012). Beliefs over Control and Meta-Worry Interact with the Effect of Intolerance of Uncertainty on Worry. Personality and Individual Differences, 53, 224-230. https://doi.org/10.1016/j.paid.2012.03.016 
Ruscio, A. M., Seitchik, A. E., Gentes, E. L., Jones, J. D., \& Hallion, L. S. (2011). Perseverative Thought: A Robust Predictor of Response to Emotional Challenge in Generalized Anxiety Disorder and Major Depressive Disorder. Behaviour Research and Therapy, 49, 867-874. https://doi.org/10.1016/j.brat.2011.10.001

Sexton, K. A., Norton, P. J., Walker, J. R., \& Norton, G. R. (2003). Hierarchical Model of Generalized and Specific Vulnerabilities in Anxiety. Cognitive Behaviour Therapy, 32, 82-94. https://doi.org/10.1080/16506070302321

Schoenleber, M., Chow, P. I., \& Berenbaum, H. (2014). Self-Conscious Emotions in Worry and Generalized Anxiety Disorder. British Journal of Clinical Psychology, 53, 299314. https://doi.org/10.1111/bjc.12047

Stapinski, L. A., Abbott, M. J., \& Rapee, R. M. (2010). Fear and Perceived Uncontrollability of Emotion: Evaluating the Unique Contribution of Emotion Appraisal Variables to Prediction of Worry and Generalized Anxiety Disorder. Behaviour Research and Therapy, 48, 1097-1104. https://doi.org/10.1016/j.brat.2010.07.012

Startup, H. M., \& Erickson, T. M. (2006). The Penn State Worry Questionnaire (PSWQ). In G. C. L. Davey, \& A. Wells (Eds.), Worry and Its Psychological Disorders: Theory, Assessment and Treatment (pp. 101-119). Chichester: Wiley.

https://doi.org/10.1002/9780470713143.ch7

Sugiura, T., Sugiura, Y., \& Tanno, Y. (2013). Relationships among Refraining from Catastrophic Thinking, Worrying, and Metacognitive Beliefs. Psychological Reports, 113, 1013-1026. https://doi.org/10.2466/02.09.PR0.113x14z3

Sugiura, T., Sugiura, Y., \& Umaoka, K. (2003). Correlates of Cognitive Control: Personality Traits, Meta-Cognitions, and Coping Styles. Journal of the Graduate School: Home Economics, Human Life Sciences, 9, 13-23.

Sugiura, Y. (2005). Problem-Solving Model of Worrying. Tokyo: Kazama Shobo.

Sugiura, Y. (2007). Responsibility to Continue Thinking and Worrying: Evidence of Incremental Validity. Behaviour Research and Therapy, 45, 1619-1628. https://doi.org/10.1016/j.brat.2006.08.001

Sugiura, Y., \& Tanno, Y. (2000). Self-Report Inventory of Obsessive-Compulsive Symptoms: Reliability and Validity of the Japanese Version of the Padua Inventory. Archives of Psychiatric Diagnostics and Clinical Evaluation, 11, 175-189.

Takebayashi, Y., Takagaki, K., \& Sugiura, Y. (2012). Development and Evaluation of the Japanese Version of Generalized Anxiety Disorder Questionnaire for DSM-IV. Archives of Psychiatric Diagnostics and Clinical Evaluation, 5, 89-98.

Thielsch, C., Andor, T., \& Ehring, T. (2015). Metacognitions, Intolerance of Uncertainty and Worry: An Investigation in Adolescents. Personality and Individual Differences, 74, 94-98. https://doi.org/10.1016/j.paid.2014.10.004

Turk, C. L., Heimberg, R. G., Luterek, J. A., Mennin, D. S., \& Fresco, D. M. (2005). Delineating Emotion Regulation Deficits in Generalized Anxiety Disorder: A Comparison with Social Anxiety Disorder. Cognitive Therapy and Research, 29, 89-106.

https://doi.org/10.1007/s10608-005-1651-1

Wada, S. (1996). Construction of the Big Five Scales of Personality Trait Terms and Concurrent Validity with NPI. The Japanese Journal of Psychology, 67, 61-67. https://doi.org/10.4992/jjpsy.67.61

Wells, A. (1995). Metacognition and Worry: A Cognitive Model of Generalized Anxiety Disorder. Behavioural and Cognitive Psychotherapy, 23, 301-320.

https://doi.org/10.1017/S1352465800015897

Wells, A. (2000). Emotional Disorders and Metacognition. Chichester: John Wiley.

Wells, A. (2006). The Metacognitive Model of Worry and Generalized Anxiety Disorder. 
In G. C. L. Davey, \& A. Wells (Eds.), Worry and Its Psychological Disorders: Theory, Assessment and Treatment (pp. 179-199). Chichester: Wiley.

Wells, A., \& Cartwright-Hatton, S. (2004). A Short Form of the Metacognitions Questionnaire: Properties of the MCQ-30. Behaviour Research and Therapy, 42, 385-396. https://doi.org/10.1016/S0005-7967(03)00147-5

Williams, K. E., Chambless, D. L., \& Ahrens, A. (1997). Are Emotions Frightening? An Extension of the Fear of Fear Construct. Behaviour Research and Therapy, 35, 239-248. https://doi.org/10.1016/S0005-7967(96)00098-8

Submit or recommend next manuscript to SCIRP and we will provide best service for you:

Accepting pre-submission inquiries through Email, Facebook, LinkedIn, Twitter, etc. A wide selection of journals (inclusive of 9 subjects, more than 200 journals)

Providing 24-hour high-quality service

User-friendly online submission system

Fair and swift peer-review system

Efficient typesetting and proofreading procedure

Display of the result of downloads and visits, as well as the number of cited articles Maximum dissemination of your research work

Submit your manuscript at: http://papersubmission.scirp.org/

Or contact psych@scirp.org 